\title{
Algunas notas sobre la introducción de la filosofía vitalista en la cultura eslovaca
}

\author{
Monika KAPRÁliKOVÁ \\ Universidad Comenius de Bratislava (Eslovaquia) \\ m.kapralikova@gmail.com
}

Recibido: Diciembre de 2011

Aceptado: Enero de 2012

\begin{abstract}
Resumen
La filosofía vitalista se introdujo en la cultura eslovaca en los años veinte y, durante un corto periodo de tiempo, marcó su influencia en las obras de varios literatos. Sin embargo hasta hoy pertenece a los temas marginales y muy poco elaborados en las publicaciones eslovacas. El presente artículo aspira a ofrecer al lector un sumario básico de los orígenes del vitalismo e interpretar brevemente su implantación en la cultura eslovaca, tal como ocurrió en el periodo de entreguerras.
\end{abstract}

Palabras clave: cultura eslovaca, periodo de entreguerras, filosofía vitalista, élan vital.

Some Notes on the Introduction of Life Philosophy in Slovak Culture

\begin{abstract}
The life philosophy was introduced to the Slovak culture in the early twenties and, during a short period of time, influenced the work of various litterateurs. Nevertheless, up to now the topic remains marginal and less elaborated as it deserves among the Slovak scholars. The present article tries to offer a basic summary of the origin and sources of vitalism in Slovakia as well as briefly interpret its implantation into the Slovak culture, as it occurred in the interwar period.
\end{abstract}

Key words: Slovak Culture, Interwar Period, Life Philosophy, élan vital.

La filosofía vitalista y su influencia para la cultura eslovaca son hasta hoy temas poco elaborados en la literatura científica eslovaca. Podemos identificar el motivo en que el vitalismo no ancló tan profundamente en nuestro entorno como, por ejemplo, en el checo. Además, el concepto cultural vitalista era solamente uno de los muchos que surgieron tras la Primera Guerra Mundial en Eslovaquia. No obstante, y a pesar de que el único autor que lo desarrolló continuamente en su obra fue el poeta, redactor y editor Ján Smrek, la filosofía de la vida, en el momento de su introducción en Eslovaquia en los años veinte y treinta, tuvo una gran repercusión en la generación joven y durante un corto periodo de tiempo influyó en varios literatos y críticos literarios. 
Hasta el momento presente ha sido Alla Mašková en su monografía El naturismo ${ }^{1}$ eslovaco en el espacio-tiempo (Slovenský naturizmus vstore) (MAŠKOVÁ 2009) la que ha prestado mayor atención a este tema. Aparte del análisis de la influencia vitalista en las obras de los "prosistas líricos", la autora presenta también una breve descripción del impacto del vitalismo en toda la literatura eslovaca. También existen numerosos estudios parciales que de algún modo tratan sobre la influencia de la filosofía vitalista en la poesía eslovaca, sobre todo en la de J. Smrek (KOVÁČ 1962; TOMČÍK 1961; PIŠÚT 1978; PETRÍK 1987; ŠMATLÁK 2001). Sin embargo, hasta ahora aún falta alguno que presente la aparición del concepto con una mayor amplitud y detalle, incluyendo datos históricos y su contexto. No cabe duda de que no puede cumplirse este objetivo con un simple artículo, sino que se precisa una monografía completa. Por el momento aspiramos, al menos, a ofrecer al lector un sumario de los orígenes y la implantación del vitalismo en la cultura eslovaca, tal como ocurrió en el periodo de entreguerras.

Las obras de los filósofos vitalistas atraían a la juventud eslovaca por su crítica del espíritu de la época, su polémica con el positivismo, así como por su intención de establecer una nueva jerarquía de valores (MAŠKOVÁ 2009: 50). Una de las primeras figuras que reflexionó sobre las ideas de la filosofía vitalista en el ambiente cultural eslovaco de principios del siglo veinte fue el redactor de la revista Slovenské pohl'ady y secretario de Matica slovenská, Štefan Krčméry. Aunque al principio estuvo más influido por los filósofos alemanes F. Nietzsche y A. Schopenhauer, ya a partir de principios de los años veinte la influencia del filósofo francés Henri Bergson estuvo presente en su obra y vida profesional. Precisamente fue Krčméry quien, gracias al peso de su autoridad, extendió las ideas del bergsonismo entre los círculos literarios eslovacos, tanto directamente, por su actividad de redactor, como por sus contactos personales con jóvenes autores. En el año 1922 publicó en su revista la reseña de la obra de Bergson La risa (KRČMÉRY 1922). Aunque el texto se refería al título original francés Le rire, lo que según Paštéka podría implicar su conocimiento de la obra en el original, las ideas reproducidas en la reseña pertenecen al capítulo tercero del texto francés, titulado "Comicidad de caracteres" (Charakterová komika), que se publicó en 1916 en traducción checa (PAŠTEKA 1974: 88). Aún más impacto que La risa tuvo en Krčméry la obra bergsoniana La evolución creadora, de 1907, que identifica la vida como una fuerza de creación infinita, un movimiento evolutivo constante o "ímpetu vital" que continuamente se crea y se enriquece. Krčméry conoció el texto probablemente ae 1919. La influencia vitalista se hizo presente enseguida no solamente en sus poemas (TOMČ́́K 1961: 271; MATUŠKA 1975: 103), sino también en sus escritos sobre la historia literaria eslovaca Historia de la poesía eslovaca (Dejiny slovenskej poézie) y Ciento cincuenta años de la literatura eslovaca (Stopät'desiat rokov slovenskej literatúry) (VANOVIČ 1994: 38-39).

\footnotetext{
1 Bajo la denominación "naturismo" se consagró en la literatura eslovaca un grupo de autores (M. Figuli, D. Chrobák, F. Švantner) que aparecieron en la literatura en los años treinta y cuyo estilo se caracteriza por metáforas y elementos del expresionismo. Su modelo se encuentra en la literatura escandinava (K. Hamsun, S. Lagerlöf) o francesa (Ch. F. Ramuz, J. Giono). Sus personajes literarios se enfrentaban a menudo al conflicto entre las normas dictadas por la naturaleza y las de la civilización. Otro término utilizado es el de "prosa lírica".
} 
Por último, Bergson pudo influir en Krčméry también por el deslumbrante estilo ensayístico en el que escribía sus obras. Así, s elementos artísticos que científicos: la fantasía artística, el brío poético, el virtuosismo metafórico superaban los datos científicos. Estas son las cualidades que podían haber atraído a ambos: al Krčméry artista igual que al Krčméry científico (PAŠTEKA 1974: 89).

En 1929, cuando Krčméry preparó un artículo sobre Bergson, quien entonces cumplía 70 años, constató sintomáticamente la influencia del pensador francés en la cultura eslovaca de esta forma: "Bergson representó en su época lo mismo que Hegel en la suya, en cuyo sistema varios de nuestros ‘šturovianos' (štúrovci) encontraron igualmente su fe" (KRČMÉRY 1929: 646). Pero Krčméry no fue el único introductor de pensamientos vitalistas en el entorno cultural eslovaco. También podemos encontrar otro, aunque únicamente para los teólogos evangélicos, en el personaje del teólogo, pedagogo e historiador de la filosofía Samuel Stefan Osuský. Tras haber defendido su tesis doctoral La Psicología de la Religión en el Departamento de Filosofía de la Universidad de Praga, volvió a comienzos de los años veinte a Eslovaquia como profesor de filosofía en la Escuela Superior Teológica de la Iglesia Evangélica de Ausburgo (Theologická vysoká škola evanjelickej ausburgskej cirkvi). Hay que añadir que a comienzos de los años veinte, como resultado de las nuevas condiciones políticas, el sistema educativo en Eslovaquia experimentaba una restructuración general y la enseñanza de la filosofía en lengua eslovaca se encontraba en sus inicios. Las clases de Osuský representaban una buena oportunidad para contactar con las nuevas ideas filosóficas - entre ellas la filosofía vitalista y el bergsonismo- gracias a su anterior formación en Erlagen, Jena, Leipzig y la antes mencionada en Praga. Según los recuerdos de sus numerosos estudiantes, Osuský era un excelente pedagogo. En el archivo se conservan varias de sus lecciones magistrales, en las que podemos documentar su estilo de enseñanza. Por desgracia solamente una de ellas está relacionada con el vitalismo, lo que no nos permite llegar a conclusiones generales. Al menos podemos citarla para mostrar como el profesor trasladaba el vitalismo a los jóvenes teólogos. La lección magistral se titula "Bergson el filósofo sobre la moral y la religión" (Bergson filozof o mravnosti a náboženstve) y fue escrita por Osuský probablemente en 1936, tras la publicación de la traducción checa de Las dos fuentes de la moral y de la religión. Principalmente trata de esta obra del pensador francés, pero Osuský la incluye en todo el contexto de la filosofía de H. Bergson y tampoco evita citar sus obras anteriores, sobre todo La evolución creadora.

Así como el ser humano continuamente cambia y sin embargo perdura, la naturaleza de la existencia es dureé —duración variable, corriente continua-. (...) Dureé es la realidad absoluta, el Dios en esta realidad absoluta representa la tendencia positiva igual que la negativa; la positiva es esfuerzo espiritual, élan vital, movimiento; la negativa es materia, cuerpo, paz, muerte. A esta índole de la existencia no accedemos con el intelecto, porque el intelecto es creación de la vida. A ella nos puede llevar solamente la intuición, igual que la intuición lleva a un artista a la creación (OSUSKÝ, s.d.: 1-2).

El ambiente cultural eslovaco también recibió el vitalismo de fuentes foráneas. En particular tuvo un papel importante Praga, la metrópolis del recientemente for- 
mado estado checo-eslovaco. Allí reinaba una atmósfera de exploración ideológica y estética, y las ideas nuevas u obras importantes resultaban fácilmente accesibles, tanto de manera inmediata como en tempranas traducciones. Sin duda era un centro intelectual en aquella época, no solo para los checos, moravos, eslovacos o rutenos. En 1926 Vilém Mathesius fundó el Círculo Lingüístico de Praga (Pražský lingvistický krúžok) que, al abrirse al publico posteriormente en los años treinta, fue conocido como la Escuela de Praga y que fue una de las tres escuelas lingüísticas más importantes de la época. Entre sus miembros se encuentran nada menos que R. Jakobson, N. S. Trubetzkoy, P. Bogatyrev, J. Mukařovský, M. Weingart, entre otros. Contra la reducción científica positivista luchó el Círculo Filosófico de Praga (Pražský filozofický krúžok), fundado en 1934 y dirigido por el conocido profesor del Departamento de Filosofía J. B. Kozák. Aunque por su estructura checo-alemana su principal enfoque era la fenomenología y la filosofía de E. Husserl, tampoco quedaron fuera de su interés los filósofos de la vida H. Bergson, W. Dilthey o A. Schopenhauer y F. Nietzsche.

A los jóvenes literatos les atraían las obras de los críticos checos dedicadas al personaje de Nietzsche. Sobre todo se interesaron en la monografía de O. Fischer Friedrich Nietzsche (1913), los textos de Z. Nejedlý de los años veinte, así como en la impresionante obra de F. X. Šalda sobre F. Nietzsche (MAŠKKOVÁ 2009: 50).

Fue muy natural que los estudiantes eslovacos que entonces estudiaban en la Universidad Carolina en Praga se quedasen impactados por las ideas contrarias al oficialmente proclamado positivismo. Michal Chorváth, el futuro crítico literario, recordaba sus estudios en el instituto eslovaco y la sorpresa que experimentó posteriormente al llegar a la Universidad de Praga de esta manera:

La atmósfera (en el instituto - M.K.) estaba saturada por el positivismo de nuestros manuales y profesores checos. El plan de estudios se componía de tal manera que un estudiante sabía algo de todo, pero nada en profundidad. El conocimiento no debería conducir a una explicación teórica de la naturaleza de los problemas científicos, sino a la práctica de las ciencias positivistas (...) Después de llegar a la universidad me encontré en un círculo de literatos jóvenes que, para mi gran sorpresa, trataban de los mismos problemas existenciales y estéticos que yo (...) Tras haber conocido a Bergson encontré también a Nietzsche y a Schopenhauer (CHORVÁTH 1960: 132, 299-300).

Estos estudiantes representaron un papel de transmisores de las ideas opuestas al positivismo durante su regreso o estancias vacacionales en Eslovaquia. Sobre todo el grupo denominado $R-10$, que según Mašková tuvo un papel importante en la profundización del conocimiento de las obras de los filósofos vitalistas en Eslovaquia (MAŠKOVÁ 2009: 49).

Todas estas influencias se reflejaron en seguida en la generación literaria entrante: tanto directamente en su producción artística como en las publicaciones. En 1923 Ján Rob Poničan publica la colección de poesía titulada Soy (Som), en la que atestigua haberse dejado inspirar por las ideas de A. Schopenhauer, F. Nietzsche y H. Bergson. Su poesía se consideraba más como "un fenómeno de la naturaleza" que como "creación artística" porque, según sus propias palabras, se creó “instintivamente" (PONIČAN 1975: 44). Otro poeta, Ján Smrek, comienza a mos- 
trar la influencia que sobre él tiene el vitalismo en 1922, en el último ciclo de su debut poético simbolista titulado Condenado a la sed eterna (Odsúdený $k$ večitej žizni). Posteriormente esa influencia manifiesta toda su plenitud con las colecciones de poesía exclusivamente vitalistas Días al galope (Cválajúce dni) de 1925, Nudos divinos (Božské uzly) de 1929, Solamente los ojos (Iba oči) de 1933 y El poeta y la mujer (Básnik a žena) de 1934. L'udo Ondrejov, poeta y también miembro del grupo R-10, escribió en 1931, profundamente inspirado por la obra de F. Nietzsche Asi habló Zaratustra, el poema Martin Nociar Jakubovie. A pesar de que ninguna editorial estuvo dispuesta a publicar su debut, el poeta decidió superar los obstáculos y lo publicó por su propia cuenta un año más tarde. Pero, a partir de los años treinta, las ideas de la filosofía de la vida se hicieron presentes también en textos literarios y otras publicaciones. Alexander Matuška, futuro crítico literario y uno de los fundadores del grupo R-10, defendió en 1934 en Praga su tesis doctoral titulada $L a$ Influencia de la filosofía de Schopenhauer en Nietzsche (Vplyv filozofie Schopenhauera na Nietzscheho). Cuatro años antes, gracias a la editorial Leopold Mazáč, Smrek había fundado en Praga una revista que objetivaba la influencia bergsoniana directamente en su título: Elán, revista de literatura y arte. En el prólogo a su primer número, en septiembre de 1930, Smrek explicaba las razones del título de la revista:

Surgió por sí mismo como única e inmediatamente posible. De hecho todo nuestro programa, tanto de los individuos como del colectivo, está condensado en este corto, vigoroso término. Originalmente en francés significa un tipo de ciervo andariego del norte (élan $=$ esp. de grand cerf du Nord), ique éste sea nuestro símbolo! Como término filosófico (Bergson: élan vital), ique el ímpetu vital, es decir el esfuerzo continuamente activo, sea nuestro programa! ¡Seamos la generación creativa, a la que caracteriza el élan vital! (SMREK 1930a: 2)

No sería adecuado decir que la revista Elán se convirtió inmediatamente tras su fundación en la plataforma del concepto cultural vitalista eslovaco. Sus objetivos principales fueron mucho más amplios: "conectar al autor con su público, ser la brújula para los lectores, ser su informador sobre la literatura y otras tareas artísticas tanto eslovacas como extranjeras" (SMREK 1930a: 2). Sin embargo, en ningún otro periódico la influencia del vitalismo estaba tan presente como en Elán. El propio Smrek escribió un prólogo en casi todos los números y en muchos de ellos estaban inmanentes las referencias al vitalismo. En el segundo número del primer año, por ejemplo, publica su artículo titulado "Unas palabras sobre el entusiasmo" (Slovo o nadšení) en el que explica el papel del "élan" en una nación. El papel del "entusiasmo", como denominaba el "élan vital", es activar la conciencia y el instinto nacional, porque "vigilan por la prosperidad cultural". El entusiasmo continuamente rebosa de una orilla a otra, del individuo al colectivo. En el organismo nacional debe haber una circulación constante, parecida a la circulación de la sangre en el cuerpo sano de cualquier animal (SMREK 1930b: 2).

En el mismo número, unas páginas más adelante, Dobroslav Chrobák publicó también un extenso artículo, "Sobre la función del arte" (O funkcii umenia), en el que analizó las ideas de los filósofos sobre la función del arte. Aunque repasa y ana- 
liza las variaciones que ha sufrido el pensamiento sobre la función del arte, hay un pensador a cuyas ideas vuelve repetitivamente: $\mathrm{H}$. Bergson. De acuerdo con Bergson niega el papel de la ciencia, la filosofía y la religión, diciendo que el pulso de la vida solamente podemos conocerlo por el arte. Como su función principal identifica la habilidad de multiplicar la vida, a la que "eleva con los exponentes y regulaciones imaginarias, por lo que nos permite penetrar con toda la conciencia y austeridad hasta los límites de su centro" (CHROBÁK 1930: 4).

La influencia vitalista en la cultura eslovaca culminó en la primera mitad de los años treinta, cuando la sustituyó la preocupación por el futuro del país y de Europa. Smrek, el único poeta absolutamente vitalista, dejó esta poética en 1934 con la colección El Grano (Zrno). A partir de este momento estuvieron presentes en su obra los temas del retorno a la tierra nativa o la naturaleza. Sin embargo, en sus otras publicaciones en Elán, la influencia del vitalismo permaneció presente hasta la extinción de la revista en 1947. En lo que respecta a otros literatos, la filosofía de la vida siguió presente solamente en las obras de los "prosistas líricos", y a lo largo de los años cuarenta fue disminuyendo continuamente hasta desaparecer. Su presencia en la cultura eslovaca fue posible solamente en la época de entreguerras, debido a la dura experiencia de la Primera Guerra Mundial y como respuesta a la extensión del positivismo. La Segunda Guerra Mundial, el desgaste de las ideas filosóficas de F. Nietzsche y el cambio de la situación política causaron su salida de la cultura eslovaca.

\section{Referencias bibliográficas}

CHORVÁTH, M. (1960): Cestami literatúry, Slovenský spisovatel', Bratislava.

CHROBÁK, D. (1930): “O funkcii umenia”, Elán: Mesačník pre literatúru a umenie, 1, pp. 3-5. KOVÁČ, B. (1962): Poézia Jána Smreka, Slovenský spisovatel', Bratislava.

KRČMÉRY, Š. (1922): “Le rire”, Slovenské pohlady, 38, pp. 118-119.

KRČMÉRY, Š. (1929): “Henri Bergson”, Slovenské pohlady, 45, pp. 646-647.

MATUŠKA, A. (1975): Za a proti I, Slovenský spisovatel', Bratislava.

MAŠKOVÁ, A. (2009): Slovenský naturizmus v časopriestore, Spolok slovenských spisovatel'ov, Bratislava.

PAŠTEKA, J. (1974): "Štefan Krčméry medzi domovom a svetom”, Biografické štúdie, 5, Matica slovenská, Martin, pp. 85-106.

PETRÍK, V. (1987): "Básnik a čas", en Noc, láska a poézia, Slovenský spisovatel, Bratislava, pp. 195-198.

PIŠÚT, M. (1978): “Ján Smrek a jeho básnický vývoj”, en Hodnoty a čas, Tatran, Bratislava, pp. 19-27.

PONIČAN, J. (1975): Búrlivá mladost' - Spomienky 1920-1938, Slovenský spisovatel', Bratislava.

SMREK, J. (1930a): "Úvodné slovo", Elán: Mesačnik pre literatúru a umenie, 1, p. 2.

SMREK, J. (1930b): "Slovo o nadšení", Elán: Mesačník pre literatúru a umenie, 2, p. 1.

SNK - Archív literatúry a umenia, f. Samuel Štefan Osuský, sign. 46.

ŠMATLÁK, S. (2001): Dejiny slovenskej literatúry, II, LIC, Bratislava.

TOMČ́́K, M. (1961): Na prelome epoch, SVKL, Bratislava.

VANOVIČ, J. (1994): "Na chválu Štefana Krčméryho", Biografické štúdie, 21, Matica slovenská, Martin, pp. 27-40. 